Journal of Social and Development Sciences

Vol. 3, No. 4, pp. 123-134, Apr 2012 (ISSN 2221-1152)

\title{
Negotiation Style Comparisons by Gender among Greater China
}

\author{
Yu-Te Tu \\ Chungyu Institute of Technology \\ suntu@ms18.hinet.net
}

\begin{abstract}
As the economics within Greater China become more internally linked together, it becomes increasingly important to understand the nuances of each culture encompassed by this term. There is very little comparing the negotiation styles of Chinese who live in Taiwan, Hong Kong, and Mainland China among themselves. To fill the gap, the present research focuses on negotiations style comparison by gender among Chinese in Taiwan, Hong Kong, and Mainland China. The population was chosen from public companies listed under the stock markets. Data was collected using an online survey technique. SPSS was used to conduct data analyses, and a variety of statistical measures were used, including descriptive statistics and MANOVA, and coefficient alphas was reported for modified instruments in order to address reliability and validity of the instrument. The study found that only the factual negotiation style showed a significant relationship with gender among the three regions. The researcher suggests that the negotiators still need to be trained in body language, strategies, temper control, international manners, and customs. A better knowledge of negotiation should be helpful in understanding business and in realizing which negotiation styles are most appropriate for a particular country. The appropriate negotiation skills can bring more competitive advantages and benefits.
\end{abstract}

Keywords: Gender, negotiation style, Greater Chinas

\section{Introduction and Background}

As the economics within Greater China become more internally linked together, it becomes increasingly important to understand the nuances of each culture encompassed by this term. Although Taiwan, Hong Kong, and Mainland China largely originate from similar cultures and shared ancestry, their negotiation styles have been greatly influenced by their different socio-political systems (Prasad \& Rumbaugh, 2003). In recent history, Mainland China has been separated politically and economically, which has had a great influence on the development of the business climate of each area. The competing evaluations of the regions also highlight the role of ethnic and cultural influences in the development of business climates. Within these areas, the styles and skills relating to business negotiations have been greatly altered by the varied socio-political systems. In conducting business, Taiwan typically follows American and Japanese practices, and Taiwan retains some connections with Japan, but in the academic world, it has also been influenced by America (Bray \& Qin, 2001). Hong Kong had been a British colony at the end of the twentieth century, and Hong Kong typically follows British practices. The characteristics in Hong Kong are different from Mainland China and Taiwan (Bray \& Qin, 2001). Mainland China has adopted the command economic system and communism since 1945 (Kemenade, 1998). As of social policies at that time were closely guided by the Soviet Union, much of the education system, and especially the university sector, was restructured along Soviet lines (Hayhoe, 1999). This continued until 1979, when Deng Xiaoping announced his "open door policy" (International Tax Review, 2007), resulting in Mainland China having more opportunities to contract with other countries. As the number of face-to-face negotiations dramatically increases, business negotiation strategies, styles, and agreements are becoming more important (Kumar, Markeset, \& Kumar, 2004). Differences in negotiating styles originate from the fact that every society places different degrees of importance on "relationship development, negotiating strategies, decision making methods, spatial and temporal orientations, contracting practices, and illicit behaviors such as bribery" (Acuff, 1997). Numerous factors can affect the results of the negotiating process. A few of these include culture, personality, gender, experience, knowledge, and education of the parties involved in the negotiation process. How can one maintain the greatest advantage in negotiating, especially when faced by numerous people with different backgrounds? Obtaining information about the other parties, and being aware of their cultural differences becomes extremely helpful to 
negotiating effectively. No one should enter into any negotiations without preparation, because a lack of preparation could result in losing the deal. There is a lot of literature comparing the negotiation styles of Chinese who live in Taiwan, Hong Kong, or Mainland China with foreigners, but there is very little comparing the negotiation styles of Chinese who live in Taiwan, Hong Kong, and Mainland China among themselves. To fill the gap, the present research focuses on negotiations style comparison by gender among Chinese in Taiwan, Hong Kong, and Mainland China.

\section{Review of the Literature}

Greater China: During the past 20 years, international business and investment among the economic areas in East Asia, including three areas referred to as "Greater China," have intensified and contributed to the area's overall economic growth (Cui, 1998). The concept of "Greater China" is a sophisticated phenomenon, defined through scholarly studies that investigated Chinese subjects within the three economies, i.e. Mainland China (PRC), Hong Kong, and Taiwan (Wang \& Zhang, 2004; Hodson, 2003; Crawford, 2000; Ogden, 1998). From a political point of view, "Greater China" encompasses Mainland China, Taiwan, Hong Kong and Macao, though many citizens within these regions feel uncomfortable with the unity implied by the label (Ziegler, 1997). In some cases, "Greater China" includes Hong Kong, Taiwan, Macao, and at times, Singapore, but excludes Mainland China (Bjerke, 1999). The economic integration and growth among Mainland China (PRC), Hong Kong, and Taiwan have occurred so rapidly that the group of countries is referred to as the Chinese Economic Area (CEA), also known as Greater China (Cui, 1998). The term Chinese Context is also sometimes used to describe this economic region (Li \& Tsui, 2002). The most common name, Chinese Economic Area (CEA), usually refers to Mainland China, Hong Kong, and Taiwan but is often broadened to include Singapore, Macao, and other areas influenced by Chinese culture. In its narrowest sense, CEA only refers to Hong Kong, Taiwan, and coastal China, mainly Guangdong and the Fujian Province (Cui, 1998). For this study, Greater China is defined as Taiwan, Mainland China, and Hong Kong.

Culture: Barbash and Taylor (1997) indicated that culture includes religion, gender, language, class, ethnicity, and sexual orientation. Since sub-cultures, cultures and super-cultures merge and evolve, while being less bounded than before; the idea of culture is more porous and varied than before (Barbash \& Taylor, 1997). "Culture is defined as a set of shared values and beliefs that characterize national, ethnic, moral and other group behavior" (Faure \& Sjostedt, 1993). One further definition of culture was put forth by Schein as a pattern of shared basic assumptions that a group learned as it solved its problems of external adaptation and internal integration, that has worked well enough to be considered valid and, therefore be taught to new members as the appropriate way to perceive, think, and feel with relation to those problems (Schein, 1997).

Negotiation: The negotiation process between the buyer and the seller is a very important matter (Neslin \& Greenhalgh, 1983), and achieving success in negotiation is one of the most challenging communicative tasks in business (Gilsdorf, 1997). In the broadest sense, negotiation is a process of communicating back and forth to discuss the issues to reach an agreement that is satisfactory to all parties involved (Foroughi, 1998; Gulbro \& Herbig, 1994). In 1994, Delivre's theoretical literature (as cited in Demers, 2002) indicated that: Negotiation is a process for managing disagreements with a view to achieving contractual satisfaction of needs. Negotiation is a process, that is, a method that consists of a number of steps. A method for managing disagreements, because the two parties could not initially agree to satisfy their needs to their mutual satisfaction. It is therefore desirable to achieve contractual satisfaction. (35). Negotiation is a kind of social interaction for reaching an agreement for two or more parties, with different objectives or interests that they think are important (Manning \& Robertson, 2003; Fraser \& Zarkada-Fraser, 2002). Cross-cultural negotiations are more complicated due to cultural factors, environments, languages, communication styles, ideologies, and customs (Hoffmann, 2001; Mintu-Wimsatt \& Gassenheimer, 2000). When conducting international business strategic alliances, business negotiation and multilateral negotiations have become essential (Graham, Mintu, \& Rodgers, 1994). Rosenberg (1989) indicated that the differences in male and female differences from early childhood as the reasons for their differences in negotiation style. Walters, Stuhlmacher and Meyer (1989) reported that female behaviors of negotiation are more cooperatively than male, and have more concern for others than male in negotiation (Calhaun \& Smith, 1999). Female experience anxiety, fear competition and want to please while male are more competitive, assertive and talk more in negotiation (Kray \& Gelf, 2009). Therefore, male reach better outcomes than female in negotiation (Kolb, 2000). 
Negotiation Process Model: Rubin and Brown (1975) indicated that the negotiation process model originated from the exchange theory set forth. This exchange theory is divided into three stages: the antecedent stage, the concurrent stage, and the consequent stage (Rubin \& Brown, 1975). The exchange theory was further revised to the negotiation process model by Graham in 1987. Graham (1987) introduced his seminal theory of the negotiation process model based on his qualitative and phenomenological studies of negotiation. This model identifies four major variables related to the negotiation process--negotiator characteristics, situational variables, process variables, and outcome phases. The major propositions in this theory are based on pre-negotiation planning and the preparation phase. These are all linked to the negotiators' characteristics such as gender, age, negotiation experience, and education, as well as situational constraints such as the level of competition and collaboration (Graham, 1987). The model developed by Graham depicting the direct and indirect relationships among concepts continues to be utilized and investigated (Peterson \& Lucas, 2001). Graham's theory is socially significant for addressing essential issues about steps that should be followed for a disciplined negotiation style. Additionally, it is useful for explaining and predicting the outcome of face-to-face negotiations. In the past few years, the theory has been adapted to show the effects of gender differences in negotiation styles for Americans and Canadians. Overall, Graham's theory has been used to examine the effect of gender, age, education, and experiences in negotiation with well-developed propositions and strong empirical support. According to the research of Howard, Blumstein, \& Schwartz in 1986, the gender of individuals engaged in negotiations will affect the communication style utilized by each individual. Women tend to use a more non-verbal and indirect communication negotiation style than do men. This negotiation style may be related to power, and those individuals who have less power or a lower status may use more non-verbal and indirect strategies during negotiation (Howard, Blumstein, \& Schwartz, 1986). Stuhlmacher and Walters (1999) conducted an empirical study of gender differences of people who are at least 14 years old from the United States and Canada in negotiation outcomes using a causal-comparative, quantitative design. The authors' literature review was thorough in its comparison of current theories concerning the effect of gender, the potential for successful task completion, and mode of communication employed. Empirical studies of homogeneity were reviewed which exposed the major gap and existing conflict regarding the overall effect of the gender of the opponent, relative power differences between negotiators, integrative potential of the task, and modes of communication. Due to this shortcoming, Stuhlmacher and Walters's study tested the proposition that males and females have a significant difference in negotiation outcomes because women receive less compensation from organizations. Overall, the results showed a significant difference between males and females in negotiation outcomes. It also suggested that the outcome of the negotiation for females in the workplace might be a factor in creating a "glass ceiling." This led to the researchers' conclusion that women may be worse negotiators or have difficulty employing the proper negotiation tactics. Despite these findings, Stuhlmacher and Walters cautioned that they combined the representatives and characteristics of the studies, and that the overall sample size was too small. In addition, their study excluded studies that employed abstract bargaining paradigms. In their conclusion, the researchers highlighted the following areas for future study: (a) the consideration of gender differences according to other dependent variables in negotiation, such as time and cost expended to resolve the conflict, and (b) an explanation of the more subjective reactions to negotiations including satisfaction, perceptions of one's opponent, and the willingness of both parties to engage in future negotiations.

Zone Definition/Surplus Allocation Model: In 2000, Korobkin introduced his seminal theory of zone definition/surplus allocation, based on his qualitative, phenomenological studies, in order to provide a more comprehensive description of negotiations. This theory identifies the following two major constructs: 1) buyers and sellers or their respective representatives who attempt to secure the most advantageous position for themselves; and 2) the negotiators of both parties who have to reach a single point within the bargaining's zone, defined as zone definition/surplus allocation. Additionally, it can help analyze or predict the behaviors of both parties. This theory successfully addresses a complex process in a relatively simple manner, thus it is a useful tool for the study of negotiation tactics. Through its application in numerous studies, the theory has emerged as the predominant theory used to examine two different types of negotiation tactics as cooperative or competitive. Pullins, Haugtvedt, Dickson and Lewicki (2000) conducted an empirical study about individual differences in intrinsic motivation and the use of cooperative negotiation tactics. The study used an experimental, quantitative design of 85 respondents recruited from two different upper-class marketing courses, and obtained 76 usable results. The literature reviewed for the study revealed a considerable gap in 
research relating to the effect of intrinsic motivation on the application of cooperative negotiation tactics. As a result, the authors created this study to test the proposition of integrative and distributive negotiation developed in 1981 by Pruitt. The study provided evidence that individual differences can be important indicators of cooperative behaviors. This led to the conclusion that people with a higher level of autonomy will make cooperative offers to practice negotiation. From this study, the authors reported that autonomous individuals are more likely to employ cooperative negotiation tactics in business relationships, and that personality plays an important role in cooperative negotiations. These findings may have implications for training, assigning, and assessing salespeople. The researchers also noted a few limitations of the study, indicating further testing is need to examine external validity with actual business partners, additional variances in initial offers and the effect of personality in actual negotiations. They generated the following areas for future study: 1) whether personality and situational factors affect the willingness to negotiate; 2) the role of experience in the current framework of the buyer-seller relationship; and 3) socially constructed aspects of gender and nationality differences, as well as other personality factors, in negotiation tactics.

Hall's High-Low Context Cultures: Hall (1976) introduced his theory of high-low context cultures based on his qualitative, phenomenological studies about communication styles. This theory stresses the influence of high-context cultures, defined as those, which rely primarily on non-verbal/informal communication; and low-context cultures, which rely on verbal/formal communication (Simintiras \& Thomas, 1998). Mintu-Wimsatt and Gassenheimer (2002) also indicated that the contexts of communication styles are embodied in high- and low-cultures. "Context variables such as individual backgrounds, associations, values and position in society need to be considered in order to comprehend the message" (Mintu-Wimsatt \& Gassenheimer, 2000). In an empirical study that tested the theory's supposition, Cohen compared high- and low-context cultures. Individuals from high-context cultures, like Japan, are "characterized as communal, face-saving, guarded in speech, preferring indirect to direct confrontation, and viewing history as living and relevant to decisions,' " while those from low-context cultures, like America, are "'characterized by their prioritization of directness, the use of language as information, and establishing the relevance of time to negotiations' " (as cited in Schehr \& Milovanovic, 1999). Cross-cultural studies like the one aforementioned are related to analyzing the effect of different elements including educational background, beliefs, art, morals, customs, laws, and economic (Evans, Hau, \& Sculli, 1989). Mintu-Wimsatt and Gassenheimer (2000) conducted an empirical study about cultural context in buyer-seller negotiations. They used a non-experimental, causal- comparative, quantitative design of industrial exporters from the United States and the Philippines. The literature review was thorough in comparing and contrasting theories about problem-solving approaches of both high and low context cultures. When empirical studies of buyer-seller negotiations were examined, the existing research revealed major differences in problem-solving approaches depending on gender and cultural background--i.e. high- or low -context culture. This resulted in Mintu-Wimsatt and Gassenheimer's study that tested Hill's proposition of high (HC) and low culture (LC). The result indicated that cultural context does not play an important role between gender and problem-solving approaches. In the same culture of HC or LC environment, there were no obvious differences between males and females in negotiations, and gender did not appear to influence cooperative problem solving. The results also suggested that a high-context culture decreases the positive influences of negotiation while using a problem-solving approach. This led to the conclusion that HC negotiators rely more heavily on cooperative problem solving than LC negotiators.

Janosik's Cross-Cultural Negotiation Model: Janosik (1987) introduced his seminal theory of cross-cultural negotiation research based on his qualitative, phenomenological studies to find the relationship between culture and negotiation. The theory also provides that no matter which approach to negotiation is applied, it is still important to understand individual variations in negotiation styles when parties attempt to negotiate cross-culturally. Janosik identified the following four approaches to identifying and classifying culture: 1) cultures as learned behaviors; 2) cultures as systems of shared values; 3 ) cultures as dialectics; and 4) culture in contexts, defined as cross-cultural negotiation research. Several subsequent empirical studies by Osman-Gani and Tan led to refinement of the theory. Through these studies, the researchers verified the propositions about different negotiation styles in different cultures. Lately, the theory has been adapted to fit cross-cultural business negotiations involving Asian managers. In one study, Osman-Gani and Tan (2002) conducted an exploratory quantitative study of cross-cultural impacts on negotiation styles of Chinese, Malay, and Indian managers living in Singapore. Their literature review comprehensively examined research 
relating to the effect of culture on the process of negotiation. Noting the shortcomings of existing research, Osman-Gani and Tan designed their study to test Janesik's propositions with regard to cross-cultural negotiation. These negotiation styles were defined by Osman-Gani and Tan as follows:

A factual style identifies facts in an unemotional manner, pays attention to details and all statements made during a negotiation, and places much importance on proof and facts as related to experience. An intuitive person is warm and animated when making statements, flexible and creative during negotiations, fluid and able to adapt to changing subjects and situations, and imaginative in projecting into the future. A normal person considers and weights facts according to a set of personal values; this person uses all the tools at his or her disposal, such as emotions, status, authority, and rewards, to come up with the best bargain. The analytical negotiator is strongly logical, tries to find cause-and-effect in all issues, and likes to weigh pros and cons thoroughly. (p. 825). The study's value lies in its ability to help people understand the similarity of negotiation styles among Chinese, Malay, and Indian managers in Singapore. Osman-Gani and Tan's analysis of the results did not reveal a large difference between the three groups in their negotiations when comparing intuitive, normative, analytical, and factual styles. These findings led to the researchers' conclusion that Chinese, Malay, and Indian managers in Singapore have no significant differences in negotiation styles.

\section{Methodology}

The study employed a non-experimental, quantitative research design to analyze gender differences among Chinese people living in Taiwan, Hong Kong, and Mainland China. The research design used was causal-comparative (exploratory) and correlational (explanatory), and was intended to examine, describe, and explore the differences and similarities of various negotiation styles in relation to the cultural differences in the three distinct geographic regions of Greater China. The research model and hypotheses are as follows:

\section{Figure 1: Research Model}

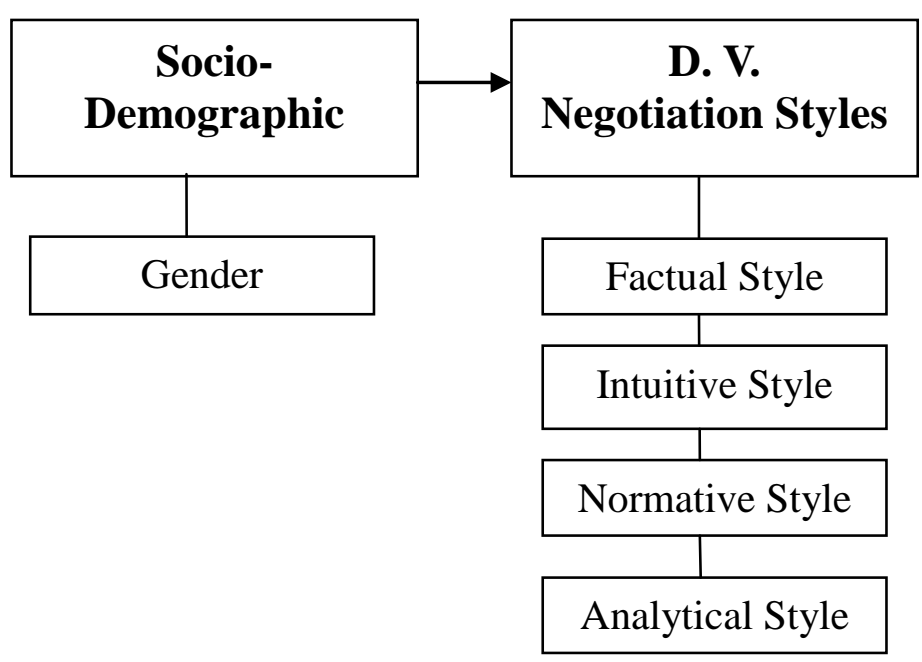

H1. There is a significant relationship between the factual negotiation style and gender of managers or negotiators of public companies in the three regions.

H2. There is a significant relationship between the intuitive negotiation style and gender of managers or negotiators of public companies in the three regions.

H3. There is a significant relationship between the normative negotiation style and gender of managers or negotiators of public companies in the three regions.

H4. There is a significant relationship between the analytical negotiation style and gender of managers or negotiators of public companies in the three regions.

The dependent variables of the model employed in this research are the four negotiation styles developed in 1985 by Dr. Pierre Casse and Dr. Surinder Deol: factual negotiation, intuitive negotiation, normative negotiation, and analytical negotiation. There are 8 questions designed to examine each negotiation style 
(factual negotiation style, intuitive negotiation style, normative negotiation style, and analytical negotiation style) that are analyzed on the five-point Likert scale. There are five options for each statement: 5 . "Always" (around 100\% of the time); 4. "Often" (around 75\% of the time); 3. "Occasionally" (around 50\% of the time); 2. "Seldom" (around 25\% of the time); 1. "Never" (around 0\% of the time). In total, there are 32 questions for the four negotiation styles. The independent variable is grnder. For the data collection of demographic variables, the participants are provides the questions as follows. Education (as a nominal variable): 1= "High School Diploma or Equivalent"; 2= "Associate Degree"; 3= "Bachelor Degree"; 4= "Graduate Degree". Religion (as a nominal variable): 1= "Buddhist"; 2= "Christian"; 3= "Moslem"; 4= "Others". Gender is defined as a dichotomous variable ( $1=$ Male; $2=$ Female). Age is defined as a nominal variable $(1=$ under $35 ; 2=35-45 ; 3=$ 46-55; $4=$ over 55). Region of birth: $1=$ "Taiwan"; $2=$ "Hong Kong"; $3=$ "Mainland China". For this study, the accessible population was chosen from public companies listed under the Taiwan Stock Exchange Corporation (TSEC), Hong Kong Exchanges and Clearing Limited (HKEx), Shenzhen Stock Exchange (SSE) and Shanghai Stock Exchange in China. There were 700 listed companies in the Taiwan Security Exchange Corporation (TSEC), and all listed companies were classified into eight sectors, including cement and ceramics, foods, plastics and chemical, textiles, electric \& machinery, paper and pulp, construction, and financial. There were 911 listed companies on the Hong Kong Exchanges and Clearing Limited (HKEx), and all companies were classified into six sectors, including financials, utilities, real estate, industries, hotels, and others. In Mainland China, there were 585 listed companies (including A stock: 530 companies and B Stock: 55 companies) in the Shenzhen Stock Exchange (SSE), and all companies are classified into six sectors, including industry, business, financials, real estate, utilities, and others. There were 872 listed companies (including A stock: 820 companies and B Stock: 52 companies) in the Shanghai Stock Exchange, and all companies were classified into five sectors, including industry, business, real estate, utilities, and others. In total, there were 3,068 listed public companies in Taiwan, Hong Kong, and Mainland China. Any company listed on these markets had the potential to be included in this study.

In order to avoid sampling errors, the population was collected from different sectors of stock markets in the three regions. A random sample was taken from each of these sectors through a stratified random sampling. Overall, this method for determining a sample population is more accurate than purely random sampling, further it allows the researcher to select a sample that accurately reflects the diverse sectors and characteristic patterns in the desired population (Wallen \& Fraenkel, 2001). This research method is useful in that it allows a small but carefully selected data pool to provide insight into the more general trends of a larger population. The principal characteristic of probability sampling is that every member or individual has an equal probability of being selected from the population as the sample (Ary, Jacobs, \& Razavier, 1996). This is also the reason why the researcher used a probability-sampling plan in this study that allowed, through use of inferential statistics, the researcher to evaluate the extent to which the findings were likely to be different from what they would have been as a result of investigating the whole population (Ary, Jacobs, \& Razavier, 1996). Under ideal circumstances, researchers could conduct studies that sample entire populations with $100 \%$ participant rates. Due to practicalities, the researcher was forced, for a variety of reasons, to find a representative sample size. Hair, Anderson, Tatham, \& Black (1998) recommended that the minimum sample size is at least five times as many as the observed variables for factor analysis. Gay and Airasian (2000) suggested that if the population is over 5,000, a sample size of 400 should be adequate. Wallen \& Fraenkel (2001) indicated that the best sample size should be as large as researchers can acquire with a reasonable expense of time and energy. Generally speaking, larger sample sizes are more likely to represent the target population (Grossnickle \& Raskin, 2001). In the research, data was collected using an online survey technique. Sheehan (2001) reported that the average response rate of online survey is $36.83 \%$. Therefore, a large number of the initial e-mail invitations for this study were sent out to ensure a large enough number of online survey responses were obtained. The number of listed companies in the stock markets in Taiwan, Hong Kong, and Mainland China was 3,068. With an accessible population of 9,204 including CEOs and sales and purchase managers, the desired sample size was 4,605 in order to increase generalization and reduce sampling errors, as suggested by Wallen, Fraenkel, Grossnickle, and Raskin in 2001.

To obtain the desired initial sample size of 4,605, 1, 535 companies were chosen, and each company's CEOs and sales and purchase managers were randomly selected from listed companies of stock markets in Taiwan, Hong Kong, and Mainland China. Invitation e-mails were sent to 4,605 participants. All information, such as the names of CEOs and sales and purchase managers, and e-mail addresses of listed companies were obtained 
through the website of the Taiwan Stock Exchange Corporation (TSEC), Hong Kong Exchanges and Clearing Limited (HKEx), Shenzhen Stock Exchange (SSE), and Shanghai Stock Exchange. The survey was accessible on the Internet without direct contact with the researcher. The CEOs and sales and purchase managers of the sample population were invited to participate via an e-mail that explained the research and included a link to the survey website. The questionnaire was posted on the website, "www.my3q.com" in English, traditional Chinese, and simplified Chinese. The researcher asked respondents to return the surveys within 30 days by sending an e-mail to "www.my3q.com" website. Three hundred and fifty companies were considered from the 700 listed companies on the Taiwan Stock Exchange Corporation. Three e-mails were sent, one of each to each company's CEOs and sales and purchase managers. There were 1050 potential respondents in total. The number of companies that were considered from the 911 listed on the Hong Kong Exchanges and Clearing Limited (HKEx) were 456. The CEOs and sales and purchase managers of each company were contacted by e-mail. The total number of potential respondents for this study from Hong Kong was 1,368. Two hundred and sixty-five companies were considered from the 530 listed on the Shenzhen Stock Exchange (SSE) of A Stock. There were 795 subjects from the Shenzhen Stock Exchange (SSE) of A Stock. Twenty-eight companies were considered from the 55 listed companies in the Shenzhen Stock Exchange (SSE) of B Stock. The CEOs and sales and purchase managers of each company were contacted by e-mail. This sample had 84 subjects. Four hundred and ten companies were considered from the 820 listed on the Shanghai Stock Exchange of a Stock. The CEOs and sales and purchase managers were contacted by e-mail. There were 1,230 subjects for this study from the Shanghai Stock Exchange of a Stock. Twenty-six companies were considered from the 52 listed in the Shanghai Stock Exchange of B Stock. The CEOs and sales and purchase managers of each company were contacted by e-mail. There were 78 subjects from the Shanghai Stock Exchange of B Stock. The Statistics Package of Social Science (SPSS) for Windows version 13.0 was used to conduct data analyses on collected data. A variety of statistical measures were used, including descriptive statistics and MANOVA. SPSS was also utilized to report coefficient alphas for modified instruments in order to address reliability and validity of the instrument.

\section{Results}

In this study, 4,605 invitations were e-mailed to public companies' CEOs and sales and purchase managers in Taiwan, Hong Kong, and Mainland China by a stratified probability-sampling plan. A hyper-link to the survey web site was provided on each invitation e-mail. Participants who chose to take part in the study were directed to the survey. Data collection lasted for one month, and 860 questionnaires were returned. However, 251 questionnaires were incomplete or invalid. A total of 609 usable questionnaires were obtained for data analysis.

Reliability Analysis: The internal consistency reliability was measured by using Cronbach's coefficient $a$ according to the mean or average correlation of each item with every other item. Initially, the internal consistency reliability of the individualist/collectivist characteristics and four negotiation styles were assessed and the reliability coefficients of each subscale as follows: 1 ) individualist/collectivist characteristics (10 items); Cronbach $\alpha=0.74 ; 2$ ) analytical negotiation styles (18 items): Cronbach $\alpha=0.87 ; 3$ ) normative negotiation styles (18 items): Cronbach $\alpha=0.75$; 4) factual negotiation styles (18 items): Cronbach $\alpha=0.85$; and 5) intuitive negotiation styles (18 items): Cronbach $\alpha=0.82$. Lin (2006) states that Cronbach's $a$ value in basic research should be at least 0.80 . For higher internal consistency reliability, four questions were removed from the questionnaire of individualist/collectivist characteristics, and the Cronbach's $a$ value became 0.81 . Eight questions were removed from the questionnaire of each negotiation style. The analytical negotiation style Cronbach's $a$ value became 0.92; the questionnaire of normative negotiation style Cronbach's $a$ value rose to 0.87; the Cronbach's $a$ value increased to 0.88; and the questionnaire of intuitive negotiation style Cronbach's $a$ value became 0.86 .

Exploratory Factor Analysis: The Kaiser-Meyer-Olkin (KMO) test and Bartlett's test had to be examined before performing factor analysis. According to Lin (2006), a KMO value larger than 0.50 is acceptable, and in 2005, Leech, Barrett, and Morgan found that Bartlett's test should be significant. The KMO value for the variables used in the study was 0.54, and Bartlett's test was significant, which means all negotiation styles in this study were sufficient for social science research and factor analysis, and could therefore be performed. For the Negotiation Style Questionnaire, 40 items were examined by principal axis factor analysis. These items 
were categorized into four negotiation styles. Each negotiation style was combined with several items that participants needed to respond to in the questionnaire. Goodwin and Goodwin (1999) indicated that if a factor loading is less than 0.30 , the variable should not be considered a part of the factor. All of the factor loadings in the study were above 0.30 , indicating that the construct validity was acceptable. Among the 609 respondents, $453(74.4 \%)$ were male and $156(25.6 \%)$ were female. In this study, 39 respondents (6.4\%) held a high school diploma or equivalent; 23 respondents (3.8\%) had an associate degree; 319 respondents $(52.4 \%)$ were college or university graduates; and 228 respondents $(37.4 \%)$ had a graduate degree. In terms of religion, 165 respondents (27.1\%) were Buddhist; 67 (11.0\%) were Christian; 38 (6.2\%) were Muslim; and 339 (55.7\%) were others. The largest number, nearly a third, 168 (27.6\%) of respondents were from Taiwan; 179 (29.4\%) were from Hong Kong; and 262 (43.0\%) were from Mainland China. Respondents' age ranged from 35 to 45 years old. There were 169 (27.7\%) respondents under 35 years old; 258 (42.4\%) between 35 and 45 years old; $132(21.7 \%)$ from 46 to 55 years old; and $50(8.2 \%)$ who were older than 55 . The value of Wilks' Lambda was $F=18.792(p<0.001)$, MANOVA for the interaction of gender and regions was significant. The Test of Between-Subject Effect, as sown in Table 1, indicated that the interaction between the gender and regions was a significant factor $(p<0.05)$ in affecting the factual negotiation style but the interaction between the gender and regions was not a significant factor $(p>0.05)$ in affecting the normative, analytical and intuitive negotiation styles.

Table 1: Test of between-subject effect of interaction for gender

\begin{tabular}{|c|c|c|c|c|c|c|c|c|}
\hline \multicolumn{8}{|c|}{ Test of Between-Subject Effect } & \\
\hline & $F$ & $P$ & & $P$ & & $\boldsymbol{P}$ & $\boldsymbol{F}$ & $\boldsymbol{P}$ \\
\hline Gender & 3.907 & 0.049 & 5.596 & 0.018 & 1. 367 & 0.243 & 18.243 & 0.000 \\
\hline Regions & 484.810 & 0.000 & 227.919 & 0.000 & 156. 925 & 0.000 & 165.795 & 0.000 \\
\hline $\begin{array}{l}\text { Gender } \\
\text { *Regions }\end{array}$ & 1.436 & 0.239 & 1.336 & 0.264 & 63.739 & 0.000 & 0.813 & 0.444 \\
\hline
\end{tabular}

H1. There is a significant relationship between the factual negotiation style and gender of managers or negotiators of public companies in the three regions.

As Table 2 presents the results of the test on the factual negotiation style, the gender in multi-variable analysis for the male group was a significant factor affecting the factual negotiation style, and the value of Wilks' Lambda was $F=208.740, p<0.001$, and the value of the Test of Between-Subject Effect was $F=22.609$, $p<0.001$. The gender in multi-variable analysis in the female group was a significant factor affecting the factual negotiation style, and the value of Wilks' Lambda was $F=183.293, p<0.001$, and the value of the Test of Between-Subject Effect was $F=349.288, p<0.001$.

Table 2: Multivariate test and test of between-subject effect on factual negotiation style for gender

\begin{tabular}{|c|c|c|c|c|c|c|}
\hline \multirow[t]{2}{*}{$\begin{array}{l}\text { Dependent } \\
\text { Variable }\end{array}$} & \multirow[t]{2}{*}{ Gender } & \multicolumn{3}{|c|}{$\begin{array}{l}\text { Multivariate Test } \\
\text { (Wilks' Lambda) }\end{array}$} & \multicolumn{2}{|c|}{$\begin{array}{l}\text { Test of Between- } \\
\text { Subject Effect }\end{array}$} \\
\hline & & $F$ & df & $P$ & & $P$ \\
\hline \multirow[t]{2}{*}{ Factual } & Male & 208.740 & 8 & 0.000 & 22.609 & 0.000 \\
\hline & Female & 183. 293 & 8 & 0.000 & 349.288 & 0.000 \\
\hline
\end{tabular}

Total mean scores of gender for each region, based on the factual negotiation style, were as follows: male $($ Taiwan $=3.745$, Hong Kong $=3.630$ and Mainland China $=3.318)$ and female $($ Taiwan $=4.044$, Hong Kong $=$ 4.236 and Mainland China $=2.596$ ) as shown in Table 3. As for the factual negotiation style, the mean difference of the Post Hoc Test of the male group, the Taiwan group had a higher significant value than for those from Hong Kong and Mainland China, and as for the female group, the Hong Kong group had a higher significant value than for those from Taiwan and Mainland China (Table 4). It means that negotiators from Taiwan in the male group prefer to employ the factual negotiation style more so than negotiators from Hong Kong and Mainland China, and negotiators from Hong Kong in the female group mostly employ the factual negotiation style more so than negotiators from Taiwan and Mainland China. 
Table 3: Estimated marginal means on factual negotiation style for gender

\begin{tabular}{lllll}
\hline Dependent Variable & Gender & Regions & Mean & $\begin{array}{l}\text { Standard } \\
\text { Deviation }\end{array}$ \\
\hline Factual & Male & Taiwan & 3.745 & 0.054 \\
& & Hong Kong & 3.630 & 0.057 \\
& & Mainland China & 3.318 & 0.041 \\
& \multirow{2}{*}{ Female } & Taiwan & 4.044 & 0.054 \\
& & Hong Kong & 4.236 & 0.043 \\
& & Mainland China & 2.596 & 0.049 \\
\hline
\end{tabular}

Table 4: Multiple comparisons of Post Hoc Tests on factual negotiation style for gender

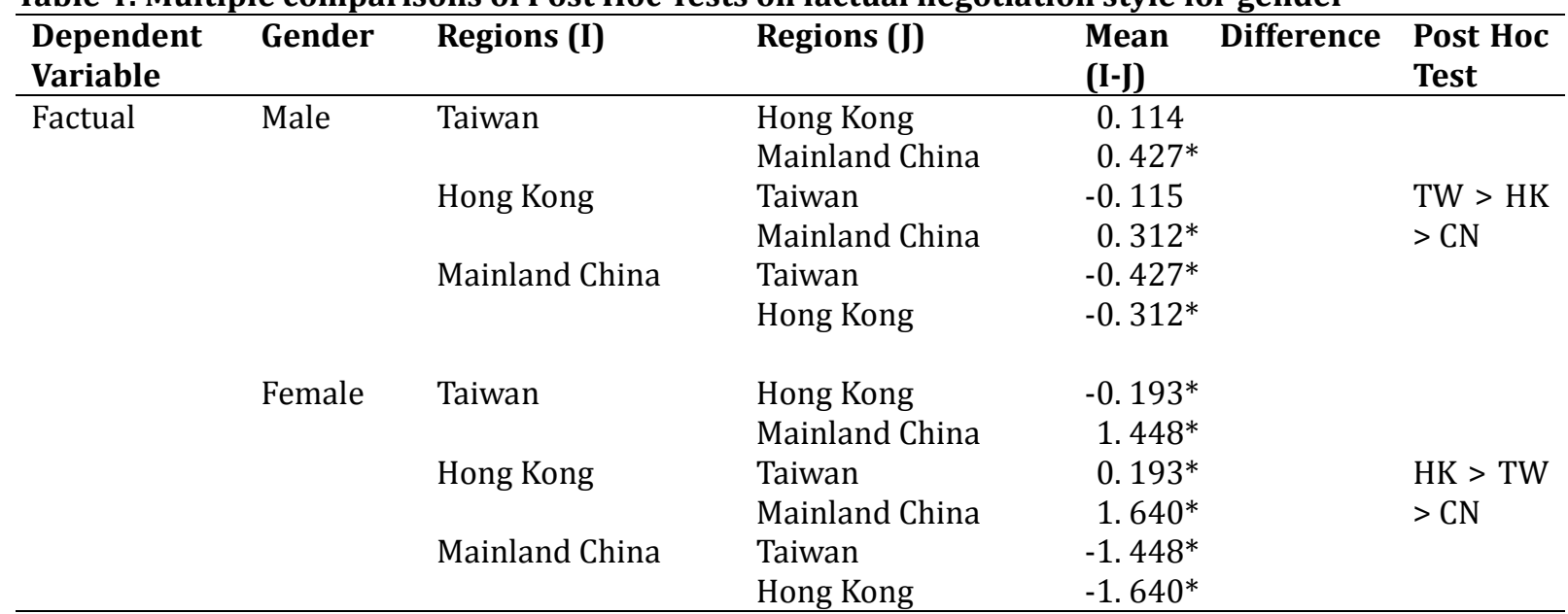

* The mean difference is significant at the .05 level.

Therefore, it can be concluded that the interaction between gender and regions is a significant variable affecting the factual negotiation style of business negotiators of the three regions.

H2. There is a significant relationship between the intuitive negotiation style and gender of managers or negotiators of public companies in the three regions.

The interaction between gender and regions is not a significant variable affecting the intuitive negotiation style of business negotiators. That is, the intuitive negotiation style of business people in the three regions does not depend on the differences in gender among the three regions (see Table 1).

H3. There is a significant relationship between the normative negotiation style and gender of managers or negotiators of public companies in the three regions.

The interaction between gender and regions is not a significant variable affecting the normative negotiation style of business negotiators. That is, the normative negotiation style of business people in the three regions does not depend on the differences in gender among the three regions (see Table 1).

H4. There is a significant relationship between the analytical negotiation style and gender of managers or negotiators of public companies in the three regions.

The interaction between gender and regions is not a significant variable affecting the analytical negotiation style of business negotiators. That is, the analytical negotiation style of business people in the three regions does not depend on the differences in gender among the three regions (see Table 1). 


\section{Discussion and Conclusion}

This study found significant differences $(p<0.05)$ of the intersection of Test of Between-Subject Effect of gender among Taiwan, Hong Kong, and Mainland China on factual negotiation style, but not for the other three negotiation styles. The factual negotiation style was correlated with gender. Taiwan negotiators who were male had a higher preference for the factual negotiation style than did male negotiators from Hong Kong and Mainland China. Hong Kong negotiators who were female had a higher preference to employ the factual negotiation style than did female negotiators from Taiwan and Mainland China. Post (2004) stated that Taiwanese girls develop aspirations at levels nearly equal to boys, compared to girls of Wuhan in Mainland China, and Hong Kong is closely following the Taiwanese experience. This may account for why all negotiators from Taiwan and Hong Kong prefer the factual negotiation style. The researcher suggests that the negotiators still need to be trained in body language, strategies, temper control, international manners, and customs. A better knowledge of negotiation should be helpful in understanding business and in realizing which negotiation styles are most appropriate for a particular country. The appropriate negotiation skills can bring more competitive advantages and benefits. Negotiators should create a data base about negotiation knowledge that can be applied in different countries. The researcher also suggests that further training and drilling are required for negotiators, and that negotiators should focus on a culture's specific requirements rather than general principles. Although the strategies would be costly in the short-term, company owners who realize the benefits of negotiation stand to gain advantages that are more competitive in the long term. The findings were limited to the public companies, and was constrained by person-power, financial resources, and time; therefore the study adopted only a quantitative research method and employed a self-reporting questionnaire to conduct the survey. Future studies could compare the differences and similarities of negotiations in several countries, such as Asia's "four little dragons" or intra regions, such as Korea or Germany.

\section{References}

Acuff, F. L. (1997). How to negotiate anything with anyone anywhere around the world. New York: AMACOM.

Ary, D., Jacobs, L. C. \& Razavier, A. (1996). Introduction to Research in Education, $5^{\text {th }}$ edition. Florida: Harcourt Brace College.

Barbash, I. \& Taylor, L. (1997). Cross-cultural filmmaking. Berkeley and Los Angeles, California: University of California Press.

Bjerke, B. V. (1999). Book review: Business decision making in China. Asia Pacific Journal of Management, $16(1), 178$.

Bray, M. \& Qin, G. (2001). Comparative education in greater China: contexts, characteristics, contrasts and contributions. Comparative Education, 37(4), 451-473.

Calhaun, P. S. \& Smith, W. P. (1999). Integrative bargaining: does gender make a difference? International Journal of Conflict Management, 10, 203-224.

Casse, P. \& Deol, S. (1985). Managing intercultural negotiations: Guidelines for trainers and negotiators. Washington, DC: International Society for Intercultural Education.

Crawford, D. (2000). Chinese capitalism: Cultures, the Southeast Asian region and economic globalization. Third World Quarterly, 21(1), 69-87.

Cui, G. (1998). The emergence of the Chinese economic area (CEA): An egocentric approach to the markets. Multinational Business Review, 6(1), 63-73.

Demers, J. (2002). Negotiating skills can be learned: An increasing number of Canadian universities are offering courses on the art - and the science - of negotiations. CMA Management, 76(8), 33. Retrieved April 13, 2004, from ProQuest database.

Evans, W. A., Hau, K. C. \& Sculli, D. (1989). A cross-cultural comparison of managerial styles. The Journal of Management Development, 8(3), 5-14.

Faure, G. O. \& Sjostedt, G. (1993). Culture and negotiation: An introduction.

Foroughi, A. (1998). Minimizing negotiation process losses with computerized negotiation support systems. Journal of Applied Business Research, 14(4), 15-27.

Fraser, C. \& Zarkada-Fraser, A. (2002). An exploratory investigation into cultural awareness and approach to negotiation of Greek, Russian and British managers. European Business Review, 14(2), 111-128. 
Gay, L. R. \& Airasian, P. (2000). Educational Research: Competencies for analysis and application. Upper Saddle River, NJ: Prentice Hall.

Gilsdorf, J. W. (1997). Metacommunication effects on international business negotiation in China. Business Communication Quarterly, 60(2), 20-38.

Goodwin, L. D. \& Goodwin, W. L. (1999). Measurement myths and misconceptions. School Psychology Quarterly, 14, 408-427.

Graham, J. L. (1987). A theory of inter organizational negotiations. Research in Marketing, 9, 163-183.

Graham, J. L., Mintu, A. T. \& Rodgers, W. (1994). Explorations of negotiation behaviors in ten foreign cultures using a model developed in the United States. Management Science, 40(1), 72-95.

Grossnickle, J. \& Raskin, 0. (2001). The handbook of online marketing research. New York, NY: The McGraw-Hill Companies, Inc.

Gulbro, R. D. \& Herbig, P. (1994). The effect of external influences in the cross-cultural negotiation process. Journal of strategic change, 3, 329-340.

Hair, J. F., Anderson, R. E., Tatham, R. L. \& Black, W. C. (1998). Multivariate data analysis (5th Ed.). Boston, MA: Pearson Education Inc.

Hall, E. (1976). Beyond culture. Garden City, NY: Anchor Press/Double Day.

Hayhoe, R. (1999). China's universities 1895-1995: a century of cultural conflict (Hong Kong, Comparative Education Research Centre, The University of Hong Kong).

Hodson, J. (2003). A case for American studies: The Michael Fay affair, Singapore-US relations, and American studies in Singapore. American Studies International, 41(3), 4-30.

Hoffmann, G. (2001). When scientists or engineers negotiate. Research Technology Management, 44(6), 13-16.

Howard, J. A., Blumstein, P. \& Schwartz, P. (1986). Sex, power, and influence tactics in intimate relationships. Journal of Personality and Social Psychology, 51(1), 102-109.

International Tax Review. (2007). Cultural evolution: the tax business in China. London: International Tax Review.

Janosik, R. J. (1987). Rethinking the culture-negotiation link. Negotiation Journal, 3, 385-395.

Kemenade, W. V. (1998). China, Hong Kong, Taiwan, Inc.: the dynamics of a new empire. Center for Strategic and International Studies (CICS) and Massachusetts Institute of Technology.

Kolb, D. M. (2000). More than just a footnote: constructing a theoretical framework for teaching about gender in negotiation. Negotiation Journal, 16(4), 347-356.

Korobkin, R. (2000). A positive theory of legal negotiation. George Law Journal, 88(6), 1789-1732.

Kray, L. J. \& Gelfand M. J. (2009). Relief versus regret: the effect of gender and negotiating norm ambiguity on reactions to having one's first offer accepted. Social Cognition, 27(3), 418-436.

Kumar, R., Markeset, T. \& Kumar, U. (2004). Maintenance of machinery: Negotiating service contracts in business-to-business marketing. International Journal of Service Industry Management, 15(3/4), 400-421.

Li, J. \& Tsui, A. S. (2002). A citation analysis of management and organization research in the Chinese context: 1984-1999. Asia Pacific Journal of Management, 19(1), 87.

Lin, R. (2006). Multivariate analysis: SPSS operation and application. Taipei: BestWise.

Manning, T. \& Robertson, B. (2003). Influencing and negotiating skills: Some research and reflections - Part I: Influencing strategies and styles. Industrial and Commercial Training, 35(1), 11-16.

Mintu-Wimsatt, A. \& Gassenheimer, J. B. (2000). The moderating effects of cultural context in buyer-seller negotiation. The Journal of Personal Selling \& Sales Management, 20(1), 1-9.

Mintu-Wimsatt, A. \& Gassenheimer, J. B. (2002). The impact of demographic variables on negotiators' problem-solving approach: A two country study. Journal of Marketing Theory and Practice, 10(1), 23-35.

Neslin, S. \& Greenhalgh, L. (1983). Nash's theory of co-operative games as a predictor of the outcomes of buyer-seller negotiations: an experiment in media purchasing. Journal of Marketing Research, 20(4), 368-379.

Ogden, S. (1998). China briefing: The contradictions of change. The Journal of Asian Studies, 57(2), 499-452.

Osman-Gani, A. M. \& Tan, J. S. (2002). Influence of culture on negotiation styles of Asian managers: An empirical study of major cultural/ethic group in Singapore. Thunderbird International Business Review, 44(6), 819-840.

Peterson, R. M. \& Lucas, G. H. (2001). Expanding the antecedent component of the traditional business negotiation model: Pre-negotiation literature review and planning-preparation propositions. Journal 
of Marketing Theory and Practice, 9(4), 37-50.

Post, D. (2004). Family resources, gender, and immigration: Changing sources of Hong Kong educational inequality, 1971-2001.Social Science Quarterly, 85(5), 1238-1259.

Prasad, E. \& Rumbaugh, T. (2003). Beyond the great wall. Finance \& Development, 40(4), 46.

Pullins, E. B., Haugtvedt, C. P. , Dickson, P. R., Fine, L. M. \& Lewicki, R. J. (2000). Individual differences in intrinsic motivation and the use of cooperative negotiation tactics. The Journal of Business \& Industrial Marketing, 15(7), 466-486.

Rosenberg, M. (1989). Society and the Adolescent Self-image. Wesleyan University Press.

Rubin, J. Z. \& Brown, B. R. (1975). The social psychology of bargaining and negotiation. New York: Academic Press.

Schehr, R. C. \& Milovanovic, D. (1999). Conflict mediation and the postmodern: Chaos, catastrophe, and psychoanalytic semiotics. Social Justice, 26(1), 208-233.

Schein, E. H. (1997). Organizational culture \& leadership. CA: Jossey-Bass Inc.

Sheehan, K. B. (2001). Email survey response rates: A review. Journal of Computer Mediated-Communication, 6(2). Retrieved from http://www.ascusc.org/ jcmc/vol6/issue2/sheehan.html

Simintiras, A. C. \& Thomas, A. H. (1998). Cross-cultural sales negotiations: A literature review and research propositions. International Marketing Review, 15(1), 10-36.

Stuhlmacher, A. F. \& Walters, A. E. (1999). Gender differences in negotiation outcome: A meta-analysis. Personnel Psychology, 52(3), 653-678.

Wallen, N. E. \& Fraenkel, J. R. (2001). Educational Research: A guide to the process (2nd Ed). Mahwah, NJ: Lawrence Erlbaum Associates, Inc.

Walters, A. E., Stuhlmacher, A. F. \& Meyer, L. L. (1989). Gender and negotiator competitiveness: a metaanalysis. Organizational Behavior and Human Decision Processes, 76, 1-29.

Wang, Q. \& Zhang, W. (2004). China's potato industry and potential impacts on the global market. American Journal of Potato Research, 81(2), 101-110.

Ziegler, D. (1997). Ready to face the world. The Economist, 342(8), 3-6. 